\title{
EXPERIMENTAL INVESTIGATIONS ON THE PERFORMANCE OF BITUMINOUS MIXES WITH RECLAIMED ASPHALT PAVEMENT (RAP) MATERIALS (CASE STUDY TUMKUR TO CHITRADURGA-NH4)
}

\author{
Sunil $\mathbf{S}^{\mathbf{1}}$, K.M.Mallesh ${ }^{2}$, T. Chandrasekaraiah ${ }^{3}$ \\ ${ }^{1}$ Post Graduate Student, Dept of Civil Engg, Siddaganga Institute of Technology, Tumkur \\ ${ }^{2}$ Associate Professor, Dept of Civil Engg, Siddaganga Institute of Technology, \\ ${ }^{3}$ Professor, Dept of Civil Engg, Dr Ambedkar Institute of Technology, Bangalore
}

\begin{abstract}
Recycling asphalt means adding the reclaimed asphalt to new asphalt mixes, with the aggregates and the old bitumen performing the same function as in their original application.

$\boldsymbol{R e}$-use asphalt means the utilization of reclaimed asphalt as foundation, fill or base course material, with the recovered aggregate and bitumen performing a lesser function than in the original application.

Recycling of hot mix asphalt (HMA) material results in a reusable mixture of aggregate and asphalt binder known as Reclaimed Asphalt Pavement (RAP). Recycling of asphalt pavements is a valuable approach for technical, economical, and environmental reasons. Using RAP has been favored over virgin materials in the light of the increasing cost of asphalt, the scarcity of quality aggregates, and the pressuring need to preserve the environment.

The present laboratory investigation carried out on Bituminous Concrete (BC) mixes prepared with 10\%, $20 \%, 30 \%$ and $40 \%$ RAP material obtained by scarifying existing distressed asphalt pavement, Surface new aggregate and bitumen such as VG-30 without using any rejuvenator. In this investigation RAP to new aggregate ratio has been adopted as 10:90, 20:80, 30:70and 40:60.Various laboratory tests such as Marshall mix design, static indirect tensile test, repeated load indirect tensile fatigue tests were carried out on RAP mix and the results were found. From the laboratory results it is observed that RAP mixes shows good Marshall Stability, Indirect tensile strength, and fatigue life similar to conventional asphalt mix.
\end{abstract}

Keywords: Recycled Asphalt Pavement, Tensile strength ratio and indirect tensile Fatigue. ***

\subsection{INTRODUCTION}

Pavement recycling is a logical and practical way to conserve our diminishing supply of construction materials and to help reduce the cost of preserving our existing pavement network. When properly designed and constructed, recycled pavements have been found to perform as well as pavements built with all new materials.

The asphalt pavement industry recycles approximately 73 million tons of material annually, which is more than twice the combined total for recycled paper, glass, plastic, and aluminum. Recycling of asphalt pavements is one of the effective and proven rehabilitation processes. It has been successfully used at many places world over and has shown satisfactory performance. Reasons to why recycling was not given importance in India during the first half of the 20th century are those of economic considerations and availability of suitable technology. The cost of new hot mix materials a few decades ago had been less than the cost of handling, transportation and reprocessing of in-situ material. Also the availability of machinery was another constraint in adopting this technology.

Recycling of worn out pavement surface has been successfully practiced in some of the developed nations and the research is still under progress to analyze various properties of the mix. Main factors in the recent year that make recycling viable are the economic factors considering the cost of bitumen and the non-availability of quality aggregates against the process cost of recycling. Thus, recycling can help in reducing the cost, conserve scarce material and reduce the amount of energy required.

Several recycling techniques, such as hot mix recycling, hot in-place recycling, cold mix recycling, cold in-place recycling, and full depth reclamation, have evolved over the past 35 years. In-place recycling not only reduces the use of new 
materials but also reduces emissions, traffic, and energy associated with the transport and production of these materials.

The most common method involves a process in which RAP is combined with virgin aggregate and virgin bitumen in a central mixing plant to produce new hot mix paving mixture. A other method namely "hot in place recycling" involves a process in which asphalt pavement surface distress is corrected by softening the existing surface with heat, mechanically removing the pavement surface, mixing it with a recycling or rejuvenating agent, possibly adding virgin bitumen and or aggregate, and replacing it on the pavement without removing the recycled material from the pavement site. The maximum limit of RAP content in conventional recycled hot mix produced in conventional hot mix asphalt batch plants is widely considered up to 50 percent, limited by both heat capacity of the plants and gaseous hydrocarbon emissions.

In the present investigation an attempt has been made to combine $10 \%, 20 \%, 30 \%$ and $40 \%$ of RAP material obtained by scarifying existing distressed asphalt pavement surface of pre mixed carpet type with virgin aggregate and soft grade bitumen such as VG-30 grade bitumen without using any rejuvenator. In this investigation RAP to new aggregate ratio Experimental Investigations on the Performance of Bituminous Mixes with a Reclaimed Asphalt Pavement(RAP) Materials. (Case study TUMKUR to CHITRADURGA-NH4) has been adopted as 10:90, 20:80, 30:70 and 40:60. The mixing is done in the laboratory manually in a heating bowl heated to a temperature in the range of 140 to $160^{\circ} \mathrm{C}$. Various laboratory tests were carried out on RAP mix and the results were compared with virgin mix.

\subsection{Importance of the Problem Selected}

Currently, great emphasis is placed on sustainable construction and infrastructure. The Leadership in Energy and Environmental Design (LEED) program has seen a dramatic increase in prominence in the past few years and public agencies across the country are modifying building construction requirements to lessen the effect of such construction on the environment. Although roadway construction is lagging in this area as compared to the building construction industry, the demand for sustainable and environmentally sound roads will increase in the future. One way to construct environmentally sound roads is through the use of recycled materials. Recycled materials have seen increasingly more use in the past 20 years.

Reclaimed asphalt pavement (RAP) is one material that has been extensively recycled. RAP is created when existing asphalt concrete surfacing is milled or completely removed. Milling the existing roadway surface and replacing it with a new Hot Mix Asphalt (HMA) is a rehabilitation method utilized throughout the country.

Here there is a result of allowing only $40 \%$ of RAP to be reused in HMA production, the quantity of unused RAP continually increases, creating opportunities for using RAP in other applications.

Dr A. Veeraragavan (Indian Road Congress 2012) conducted on Investigation on Laboratory Performance of Bituminous Mixes with Reclaimed Asphalt Pavement Materials. The primary objectives were (1) to estimate the bitumen and aggregate demand to fulfill the gradation and volumetric requirements of recycled mix, for a typical highway project. (2) to carry out mix design with recycled and virgin materials and compare the mix properties. (3) to investigation the influence of recycled materials on the mechanical behavior, tensile strength, durability and performance of bituminous mixes through laboratory experiments.

From this investigation, the authors concluded the following

a) Use of recycled materials brings about $78 \%$ reductions in the optimum bitumen content required for air voids level of $4 \%$ for a typical road project considered in the present investigation.

b) Indirect tensile strength results confirm that the use of recycled materials in bituminous mix offers high fatigue cracking resistance similar to that of virgin mixes

c) The bituminous mixes with recycled materials are found to offer higher resistance to rutting when compared with virgin materials.

Dr R. Sathikumar (National Technological Congress 2011) conducted on Reclaimed Asphalt Pavement Technology for a Sustainable Pavement. The primary objectives were conducted on RAP (1) to study about the RAP technology as a renewable resource. (2) to study mix design approach for hot recycled RAP.

From this investigation, the authors concluded the following

a) The resilient modulus and Marshall Stability values were higher for the virgin mixtures than the RAP mixtures.

b) The cost of construction using recycled mix was economical compared to virgin mix.

Iswandaru Widyatmoko (ELSEVIER Sep 2006) conducted on Mechanistic-empirical mixture design for hot mix asphalt Pavement recycling. The laboratory prepared mixtures containing RAP tend to have slightly lower stiffnesses than those from control mixtures without RAP. Mixtures containing RAP showed lower resistance to permanent deformation than that from control mixtures without RAP. The fatigue resistance of the recycled mixtures appears to be at 
least similar to or better than that of the control mixtures without RAP.

Baron Colbert \& Zhanping You (ELSEVIER 26 July 2011) conducted on The determination of mechanical performance of laboratory produced hot mix asphalt mixtures using controlled RAP and virgin aggregates size fractions. The objective of this study was to investigate the influence highly fractioned Rap has an asphalt mixture performance. (1) Analyze the effects which controlling the size fractions of RAP would affect the mechanical performance of RAP mixtures. (2) Compare mixture resilient modulus and dynamic modulus performance for high RAP percentage mixtures versus the control mixture.

From this investigation, the authors concluded the following

a) Considering total mixture resilient modulus results it can be concluded with that the fractionation of RAP mixtures, mixture stiffness can be retained better versus the control mixture.

b) RAP materials contribute towards asphalt mixture strength compared to the control mixture in an unsaturated condition and for saturated mixtures.

Louay N. Mohammad \&Samuel B. Cooper (ASCE Journal NOV 2011) conducted on Characterization of HMA mixtures containing High Reclaimed Asphalt Pavement content with Crumb Rubber additives. This study characterized the laboratory evaluation of conventional HMA mixtures and those containing high RAP content, waste tire Crumb Rubber, and engineered additives. The addition of the crumb rubber additives softened the blended asphalt content for the HMA mixture with high RAP content as determined by rheological testing of the asphalt cement extracted from the mixture. Considering moisture resistance, the CR modified asphalt mixture prepared with high RAP content performed adequately.

\subsection{Objectives of the Present Project}

1. Marshall Mix design with conventional materials added by controlled RAP.

2. Evaluation of the mechanical properties of the bituminous mix with various proportions of the RAP. (Mechanical behavior, tensile strength, durability and performance of bituminous mixes through laboratory experiments)

3. Cost analysis.

\subsection{Scope}

1. Characterization of the conventional asphalt and aggregate.

2. Characterization of the Reclaimed asphalt and aggregate.

3. Marshall Method of mix design for original aggregates and determination of properties.
4. Laboratory investigation on Marshall Properties using the reclaimed asphalt materials at variable percentages.

5. Performance Evaluation by ITS and Fatigue test.

\section{LABORATORY STUDIES}

Aggregates: Aggregate samples of sizes $26.5 \mathrm{~mm}$ down 19 $\mathrm{mm}, 12.5 \mathrm{~mm}$ down and Quarry dust are collected from the crusher and RAP materials from the field and sampled aggregates are characterized for the following properties as per MORTH specification.

Bitumen: Source of the Bitumen used for the project work is Mangalore Refineries and petrochemicals Ltd. (MRPL) and Grade selected is 60/70.The bitumen is tested in the laboratory as per the procedure laid in the IS code: 73 .

Reclaimed asphalt pavement (RAP): is a reusable mixture of aggregate and asphalt binder, source the RAP material is collected in the project (TUMKUR to CHITRADURGANH4) by IRB.

\subsection{Determination of Binder Demand}

The approximate bitumen demands of the combined aggregates of the target wearing coarse mixtures containing RAP were calculated from the following empirical formula:

$$
\mathrm{Pb}=0.035 \mathrm{a}+0.045 \mathrm{~b}+\mathrm{Kc}+\mathrm{F}
$$

Where, $\mathrm{a}=\%$ of mineral aggregate retained on $2.36 \mathrm{~mm}$ sieve, $\mathrm{b}=\%$ of mineral aggregate passing on $2.36 \mathrm{~mm}$ sieve\& retained on $75 \mu$ sieve, $c=\%$ of mineral aggregate passing on $75 \mu$ sieve, $\mathrm{K}=0.15$ for $11-15 \%$ passing $75 \mu$ sieve, 0.18 for $6-10 \%$ passing $75 \mu$ sieve, 0.2 for $5 \%$ or less passing $75 \mu$ sieve, $\mathrm{F}=0-2 \%$ based on absorption of light or heavy aggregate, 0.7 for other aggregate

RAP Bitumen extraction: The bitumen extraction is carried out for the target wearing coarse mixtures containing RAP by the extraction formula:

$$
\% \text { extraction }=((\mathrm{W} 1-\mathrm{W} 2) \backslash \mathrm{W}) \times 100
$$

Where Wt of the sample (W)gm ,Wt of the sample+ bowl(before extraction) (W1) gm, Wt of the sample+ bowl(after extraction) (W2)

Aggregate Gradation: The gradation obtained using 26.5$19 \mathrm{~mm}, 19-12.5 \mathrm{~mm}, 12.5-4.75 \mathrm{~mm}, 4.75 \mathrm{~mm}$ stone dust along with MoRT\&H specified gradation is shown in fig below Figure for Virgin and Reclaimed aggregates. 
Gradation Curve obtained at JMF for the Virgin aggregates

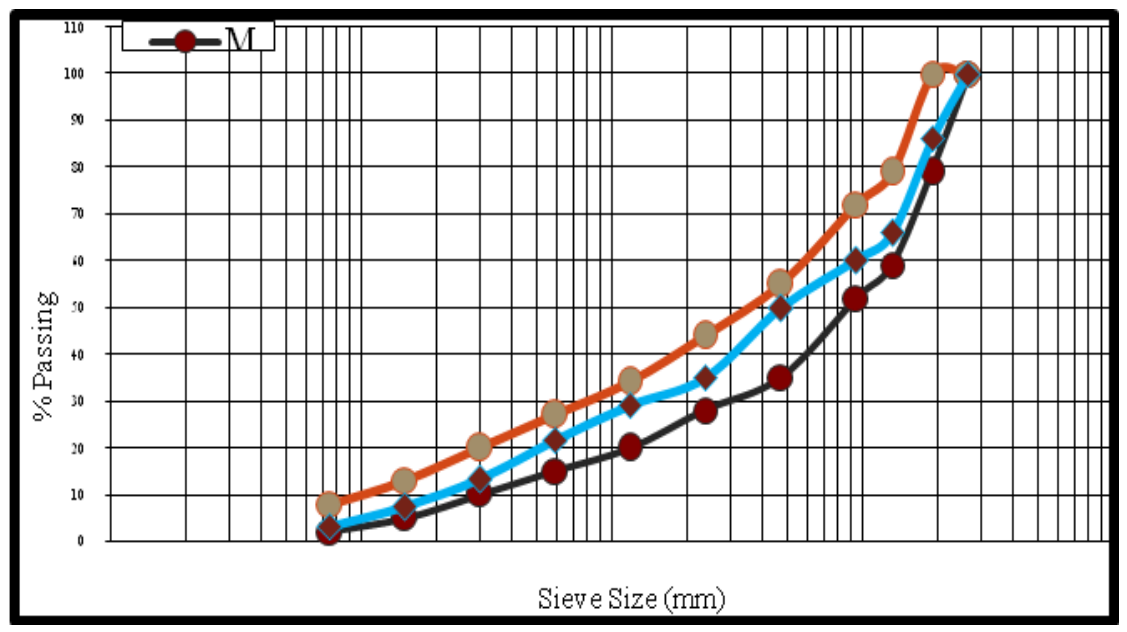

Fig 1: Gradation curve for Virgin aggregates

Gradation Curve obtained at JMF for the RAP aggregates

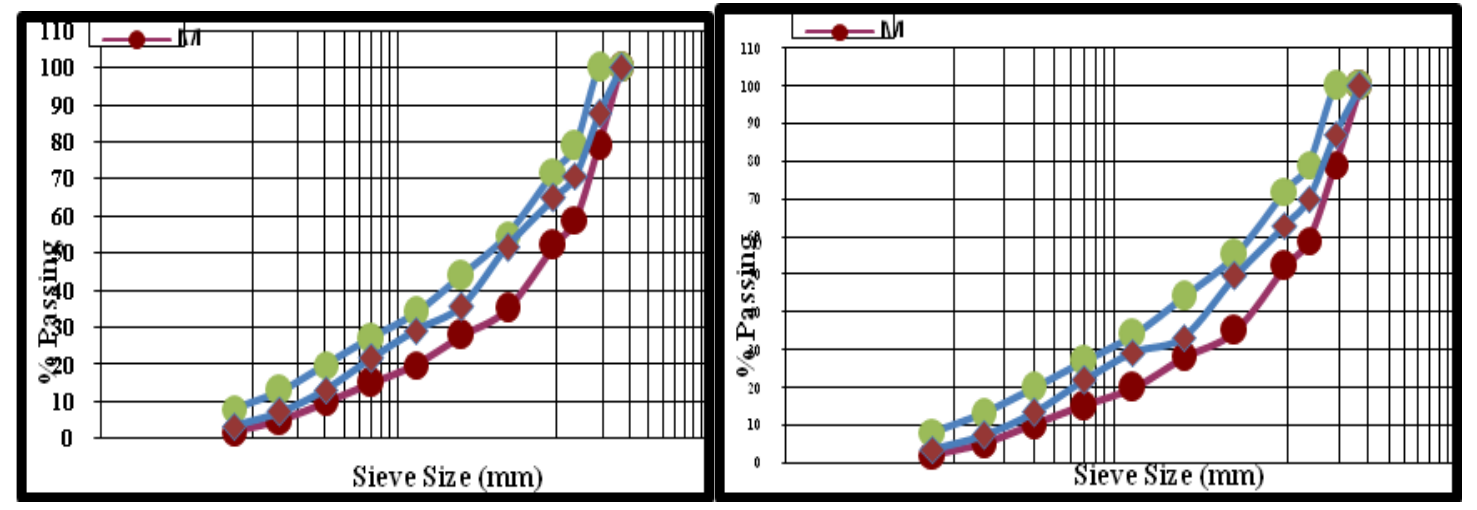

Fig 2 \& 3: Gradation curve for RAP aggregates of $10 \%$ and $20 \%$

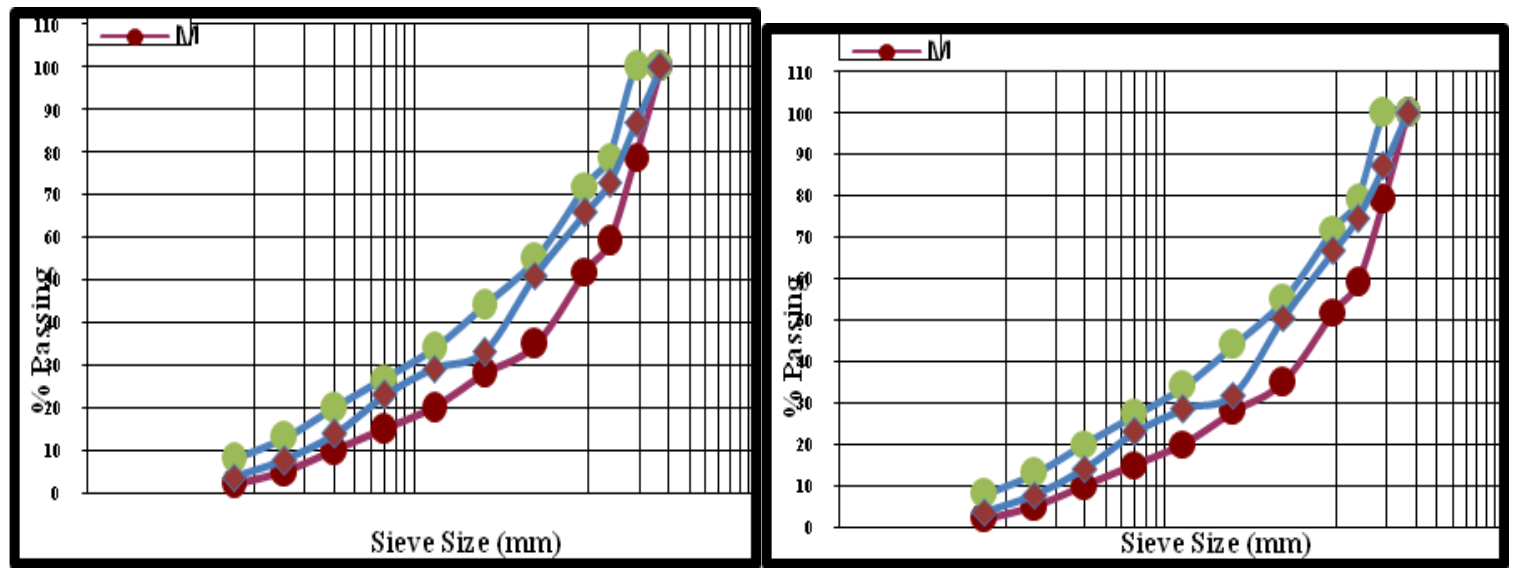

Fig 4 \& 5: Gradation curve for RAP aggregates of 30\% and $40 \%$ 


\subsection{Marshall Method of Mix Design}

The principle of the Marshall stability is the resistance to plastic flow of cylindrical specimens of a bituminous mixture loaded on the lateral surface. It is the load carrying capacity of the mix at $600 \mathrm{C}$ and is measured in $\mathrm{KN}$. The desirable mix properties include stability, density, durability, flexibility, resistance to skidding and workability during construction. Mixture Designs will be performed using the Marshall method by preparing and compacting samples with Bitumen content varied in $0.5 \%$ increments according to "ASTM Test Method for Resistance to Plastic Flow of bituminous Mixtures Using Marshall Apparatus".Bituminous concrete gradation as per MORT\&H Specification is selected. VG-30 Bitumen binder will be used. Specimens will be compacted with 75 blows on each side. Three samples will be made for each bitumen content. The optimum Bitumen content was chosen as the bitumen content that produced $4.5 \%$ air voids.
Marshall Graphs were plotted for air voids, VMA, VFB, Stability flow and density and Optimum binder content was determined for all the four cases of particle index. As per the guidelines of MS-2 Bitumen content corresponding to median of air voids percentage $(4.5 \%)$ is read from the graph and all other parameters are checked for that binder content so as to confirm that whether all other parameters such as VMA, VFB, Stability and flow falls within the MORT\&H specified limits. From the Experimental investigations for four different $\%$ of RAP materials i.e. $10 \%, 20 \%, 30 \%$ and $40 \%$ was obtained at OBC $\%$ of 5.1 and then we find out the air voids, stability, VMA, VFB. A total of 9 Marshall Specimens, 3 specimens each were prepared at OBC for RAP materials 10\%, 20\%, $30 \%$ and $40 \%$ and tested for bulk density, stability, flow, air voids, VFB and VMA. The values along with the MORT\&H Specifications are given in Table 7 and 7.1.

Table 7 and: Physical properties of BC mix for Virgin material

\begin{tabular}{|c|c|c|c|c|c|}
\hline \multirow{2}{*}{ Properties } & \multicolumn{5}{|l|}{ VG-30 } \\
\hline & 4.5 & 5 & 5.5 & 6 & 6.5 \\
\hline Bulk density (gm/cc) & 2.361 & 2.370 & 2.367 & 2.364 & 2.362 \\
\hline Stability (kg) & 1278.18 & 1452.48 & 1549.30 & 1394.38 & 1268.49 \\
\hline Flow $(\mathrm{mm})$ & 2.4 & 3.7 & 3.9 & 4.4 & 5.1 \\
\hline Air Voids (\%) & 5.68 & 4.58 & 4.12 & 3.3 & 2.44 \\
\hline $\operatorname{VMA}(\%)$ & 16.41 & 16.54 & 17.24 & 17.62 & 17.97 \\
\hline VFB (\%) & 65.38 & 72.31 & 76.11 & 81.26 & 86.4 \\
\hline
\end{tabular}

Table 7.1: Mix Properties for Virgin materials and varying different $\%$ of RAP

\begin{tabular}{|c|c|c|c|c|c|c|}
\hline \multirow[b]{2}{*}{ Properties } & \multirow[b]{2}{*}{ VG-30 } & \multicolumn{4}{|c|}{ VG-30 with RAP } & \multirow[b]{2}{*}{$\begin{array}{l}\text { MORTH } \\
\text { Specification }\end{array}$} \\
\hline & & $10 \%$ & $20 \%$ & $30 \%$ & $40 \%$ & \\
\hline $\mathrm{OBC}(\%)$ & 5.1 & 5.1 & 5.1 & 5.1 & 5.1 & Min-5 \\
\hline $\begin{array}{ll}\text { Bulk } & \text { density } \\
(\mathrm{gm} / \mathrm{cc}) & \end{array}$ & 2.369 & 2.367 & 2.366 & 2.364 & 2.362 & - \\
\hline Stability $(\mathrm{kg})$ & 1475 & 1237.40 & 1314.73 & 1401.74 & 1440.41 & $900 \mathrm{~kg}$ \\
\hline Flow $(\mathrm{mm})$ & 3.3 & 3.3 & 3.1 & 2.8 & 2.4 & $2-4$ \\
\hline Air Voids (\%) & 4.5 & 4.5 & 4.57 & 4.61 & 4.65 & $3-6$ \\
\hline VMA (\%) & 16.9 & 16.9 & 17.2 & 17.37 & 17.46 & Min-16 \\
\hline VFB $(\%)$ & 72 & 72.01 & 72.99 & 73.29 & 74.03 & $65-75$ \\
\hline
\end{tabular}

\subsection{Indirect Tensile Strength}

Test was conducted for Virgin and varying $\%$ of RAP are tabulated in the Table 8.The ASTM T283 code specifies 80 percent should be the minimum value of Indirect Tensile Strength ratio. In the following Table 8 
Table 8: Indirect tensile strength test results

\begin{tabular}{|l|l|l|l|}
\hline \multirow{2}{*}{ Type of mix } & \multicolumn{2}{|l|}{ Avg Indirect tensile strength, Mpa } & \multirow{2}{*}{ TSR\% } \\
\cline { 2 - 3 } & Unconditioned & Conditioned & \\
\hline VG-30 & 0.656 & 0.621 & 94.66 \\
\hline VG-30 + RAP 10\% & 0.681 & 0.642 & 94.27 \\
\hline VG-30 + RAP 20\% & 0.693 & 0.648 & 93.50 \\
\hline VG-30 + RAP 30\% & 0.716 & 0.661 & 92.31 \\
\hline VG-30 + RAP 40\% & 0.728 & 0.668 & 91.75 \\
\hline
\end{tabular}

\subsection{Fatigue Life Cycle for Different Particle Index:}

Test was conducted for different stress ratios $0.6,0.7$ and 0.8

for Virgin and different \% of RAP

Table 9: Fatigue cycle results for Virgin and different \% of RAP

\begin{tabular}{|c|c|c|c|}
\hline Sl No & Materials & Stress level in \% & No of cycle \\
\hline \multirow{3}{*}{1} & \multirow{3}{*}{ Virgin materials } & 60 & 1406 \\
\hline & & 70 & 985 \\
\hline & & 80 & 719 \\
\hline \multirow{3}{*}{2} & \multirow{3}{*}{$10 \%$ RAP } & 60 & 1317 \\
\hline & & 70 & 893 \\
\hline & & 80 & 661 \\
\hline \multirow{3}{*}{3} & \multirow{3}{*}{$20 \%$ RAP } & 60 & 1214 \\
\hline & & 70 & 836 \\
\hline & & 80 & 619 \\
\hline \multirow{3}{*}{4} & \multirow{3}{*}{$30 \%$ RAP } & 60 & 1156 \\
\hline & & 70 & 749 \\
\hline & & 80 & 532 \\
\hline \multirow{3}{*}{5} & \multirow{3}{*}{$40 \%$ RAP } & 60 & 978 \\
\hline & & 70 & 701 \\
\hline & & 80 & 478 \\
\hline
\end{tabular}

\section{ANALYSIS OF TEST RESULTS AND DISSCUSSION}

\subsection{Comparison of Marshall Properties at different RAP Percentages added to OBC}

After finding the $\mathrm{OBC}$ at the various percentages of the Rap material i.e., $10 \%, 20 \%, 30 \%$ and $40 \%$ are added to the OBC found for base bitumen VG-30 the percentage reduction in the bitumen content like $0.3,0.6,0.9$ and $1.2 \%$ of Bitumen content is reduced respectively.

\subsection{Stability Analysis b/w Virgin Mixes and Reclaimed Mixes $(10 \%, 20 \%, 30 \%$ and $40 \%)$}

The Marshall Stability value has been on the decreasing trend with increasing RAP bitumen this may be attributed to the fact that the Virgin bitumen may fail to rejuvenate the RAP binder as its percentage increases. Though these are the trend, there has not been much variation between the Stability values for virgin binder or add to $20 \%$ to $30 \%$ RAP bitumen. 


\subsection{ITS Ratio Analysis b/w Virgin Mixes and Reclaimed Mixes $(10 \%, 20 \%, 30 \%$ and $40 \%)$}

The Tensile strength ratio of recycled and virgin mixes can be observed that recycled mix as lower TSR when compared to virgin mix. However, even recycled mix fulfilled the minimum criteria (80\%). This indicates recycled mixes are moisture susceptibility.

\subsection{Fatigue Cycle Analysis b/w Virgin Mixes and} Reclaimed Mixes $(10 \%, 20 \%, 30 \%$ and $40 \%)$

Fatigue test is conducted to know the behavior of pavement. In this study fatigue test is conducted for three different stress ratios i.e., $60 \%, 70 \%$ and $80 \%$ for virgin and different $\%$ of recycled mixes. Fatigue cycle of recycled mixes slightly decreases when compared to virgin mixes. But this recycled mixes fulfill the requirement. This indicates that recycled mixes can resist the deformation of pavement.

\subsection{Cost Analysis}

Utilizing the RAP with a proper process have clearly shown the study that about $20 \%$ and $30 \%$ of the cost of the wearing courses or binder courses can be effectively reduced with all the other liabilities.

\section{CONCLUSIONS}

1. The aged bitumen has shown the available paving material at different percentages of the virgin binder. There has been consistent increase in the physical properties (Penetration, Ductility, softening point etc) of the old bitumen when rejuvenated with Virgin VG-30.

2. The proportioning of the aggregates with reclaimed aggregates at all specified percentages of 10,20,30 and 40 have given correct blending of the aggregates meeting the specification requirements.

3. In this present project work, based on the laboratory studies it can be concluded that more than $10 \%$ and less than $40 \%$ RAP can be suitable adopted in making the new roads with the RAP. These percentages of the RAP will differently provide an insight to a researcher or field persons to adopt effectively with proper technical alignments for Milling, Mixing, Transporting, Laying and Compacting.

\section{SCOPE FOR FUTURE STUDIES}

1. Further investigation can be carried out for more than $40 \%$ of the RAP materials with respect to reducing the Virgin materials and their Marshall Properties, ITS and Fatigue test behavior can be evaluated.
2. Performance based test methods can be carried out are Static or Creep, Dynamic loading and Rutting tests to provide accurate and realistic relationship.

3. Repeated loading test can be carried for different Stress ratio from $10 \%$ to $100 \%$.

\section{REFERENCES}

[1] Dr A. Veeraragavan," Investigation on Laboratory Performance of Bituminous Mixes with Reclaimed Asphalt Pavement Materials", Indian Road congress 2012.

[2] Dr R. Sathikumar, "Reclaimed Asphalt Pavement Technology for a Sustainable Pavement",National Technological Congress 2011.

[3] Iswandaru Widyatmoko," Mechanistic-empirical mixture design for hot mix asphalt Pavement recycling”, ELSEVIER Sep 2006.

[4] Rodrigo Miro \& Gonzalo valdes, "Evaluation of high modulus mixture behavior with high reclaimed asphalt pavement percentages for sustainable road construction”,ELSEVIER May 2011.

[5] Louay N. Mohammad \& Samuel B. Cooper, "Characterization of HMA mixtures containing High Reclaimed Asphalt Pavement content with Crumb Rubber additives", ASCE Journal NOV 2011.

[6] Baron Colbert \& Zhanping You, "The determination of mechanical performance of laboratory produced hot mix asphalt mixtures using controlled RAP and virgin aggregates size fractions", ELSEVIER 26 July 2011.

[7] Alexander Bernier \& Adam Zofka," Laboratory evaluation of rutting susceptibility of polymer modified asphalt mixtures containing recycled pavements", ELSEVIER JAN 2012.

[8] Pietro Leandri \& Giamco Cuciniello," Study of Sustainable high performance bituminous mixtures", ELSEVIER 2012. 